\title{
A Study on the Effect of Students' Perception of Teachers' Positive Discipline on Bullying Prevention in Primary Schools in the Taiwan Region
}

\author{
Lung-Fan Wei, Shu-Hsuan Chang, and Chung-Yu Lin
}

\begin{abstract}
Positive discipline by educators is helpful for the development of good behavior in primary school students. The process of positive discipline is affected by the emotional intelligence of the students themselves. However, as it can produce changes in students' relationships with peers, the quality of peer relationships is also an important factor determining whether students experience bullying. Thus, the goal of this study was to analyze the linkages between senior primary school students' perception of teachers' positive discipline and those of being bullied in the Taiwan region. At the same time, this study aimed to explore the mediator effects of peer relationships and students' emotional intelligence on these linkages. The subjects of this study were 1,110 senior primary school students ( 565 male, 545 female; average age of 11.45 years). The research tools employed included a self-report scale to assess senior primary school students' perception of the levels of teachers' positive discipline, display of emotional intelligence, level of peer relationships, and perception of being bullied. This study propose research conclusions and concrete recommendations for the improvement of teachers' positive discipline, for the development of students' emotional intelligence and peer relationships, and for the development of appropriate education strategies in general.
\end{abstract}

Index Terms-Emotional intelligence, peer relationships, perception of being bullied, positive discipline.

\section{INTRODUCTION}

Positive discipline refers to teachers using a positive attitude and positive thinking methods to lead students to change themselves, overcome obstacles, and display appropriate behaviors; and to help students to develop self-respect and self-control, and to establish harmonious and healthy relationships with others [1]. Bullying behaviors are most harmful to primary school students; those who have been bullied may always retain the role of the victim of bullying, and the bullying itself may lead to negative impacts on the victim's peer relationships [2]. Thus, positive discipline by teachers is helpful for facilitating the development of good peer relationships among students and improving student behavior through self-control, thereby reducing incidences of bullying. Furthermore, good peer relationships help preventing bullying. However, conversely, poor peer relationships may easily result in the creation of bullying incidents, which can lead to to a vicious circle of

Manuscript received May 8, 2017; revised November 2, 2017.

The authors are with the National Changhua University of Education, Changhua City, Taiwan (e-mail: e12048@yahoo.com.tw). such relationships [3]. Thus, whether or not peer relationships play a mediating role in the effect of teachers' positive discipline on student bullying is a question worthy of further study.

Emotional intelligence is the ability to maintain self-control, enthusiasm, and persistence, and the ability to motivate oneself. The development of emotional intelligence is relatively important with reference to career development; herein, peer relationships play an important role. Studies on children, which examined the relationship between emotional intelligence and peer relationships, revealed a positive correlation between emotional intelligence and peer relationships [4], [5]. The level of emotional intelligence is positively correlated with one's ability to control inappropriate bullying behavior [6], [7]. Thus, exploring the moderating role of emotional intelligence in peer relationships and the perception of being bullied is helpful for understanding the value of emotional intelligence in preventing bullying.

\section{LITERATURE REVIEW}

\section{A. Positive Discipline by Teachers and Perceptions of Being Bullied}

In her study on managing bullying during classroom management, Allen, K. P. (2010) pointed out that the way in which a teacher treats his/her students can be expressed through the teacher's classroom management behaviors. Furthermore, the existence of a bullying atmosphere within a classroom can be linked to the teacher's disciplining methods [8]. Therefore, the methods that a teacher uses for classroom control could be helpful for advocating and promoting the prevention of bullying. Through positive discipline and encouragement, by teaching students how to communicate rationally and actively help others, and to help them manage interpersonal relationships, one can nurture students' sense of responsibility and ethics, their willingness to help others, and their self-esteem and respect when handling problems. Additionally, one can help them learn to establish empathy. They can be helped to truly face themselves, and actively and positively consider ways to prevent the occurrence of bullying [9]. In the teaching process, "positive behavioral support" emphasizes on the establishment of a positive behavioral environment with respect for students' human rights, which allows individuals to have more positive influence when managing and preventing negative factors as a result of the teachers' ability to apply empathetic methods with counseling techniques. In this way, the expert 
application of positive forces, while avoiding unlawful methods of punishment, is helpful for improving students' academic performance and stimulating their learning potential, thereby helping students to achieve physical and mental harmony [10]. Considering the viewpoints of academics in the above described research, we proposed the first hypothesis of this study:

Hypothesis 1: Positive discipline by teachers has a negative effect on students' perceptions of being bullied.

\section{B. Positive Discipline by Teachers and Peer Relationships}

Peer relationships not only have important effects on students' life adaptation, but they can also interfere with their academic performance. This type of relationship can fulfill students' specific emotional needs and it provides positive social support, which in turn can be more helpful for student development and psychological health through interactive studying [11]. Early research has also proven that when emphasizing the use of positive and preventive methods, students can make changes in their problem behaviors through behavioral training [12]. Sugai et al. (2010) noted that school-wide positive behavioral support is the most effective intervention method for promoting students' desirable behavior in the society, educational environments, and in school [13]. Thus, positive discipline by teachers provides social environmental support and interpersonal interactive support to improve students' ability to develop healthy peer relationships at school. In summary, this study believes that positive discipline by teachers is helpful for improving students' peer relationships, and based on this finding, we proposed our second research hypothesis:

Hypothesis 2: Positive discipline by teachers has a positive and statistically significant effect on peer relationships.

\section{Positive Discipline by Teachers, Peer Relationships, and Perceptions of Being Bullied}

Victims of bullying, when compared with other children, are more obedient, retreated, and isolated; have less leadership skills; are less cooperative and social; have fewer friends; and are more likely to prefer playing alone [14]. Victims of bulling express a strong sense of isolation [15]. When a victim of bullying is helped to improve interactive relationships with peers through the positive discipline of teachers, this will change the victim's future emotional health, social interaction, and quality of life, thereby reducing the incidence of bullying [16]. Students with poor peer relationships are more likely to develop psychological illnesses such as anxiety, depression, schizophrenia, and personality disorders [17], [18]. Furthermore, these students with poor peer relationships are also more likely to exhibit poor adaptability to school situations, for example: dropping out, becoming involved with areas related to crime, and bulling problems [19]. In summary, this study revealed that peer relationships have an effect on the perception of being bullied, and that peer relationships have a mediating effect on teachers' positive discipline and perceptions of being bullied; based on this, we proposed our third and fourth research hypotheses:

Hypothesis 3: Peer relationships have a statistically significant and negative effect on perceptions of being bullied.

Hypothesis 4: Positive discipline by teachers affects perceptions of being bullied through the mediating effect of peer relationships.

\section{Emotional Intelligence, Peer Relationships, and Perceptions of Being Bullied}

Emotional intelligence is a type of manifestation of social intelligence. It includes examining one's and others' feelings and emotions and judging differences between these while also using this information to guide one's own thoughts and actions [20]. From this literature, we can reasonably deduct that levels of emotional intelligence affect interactive relationships with peers, and thereby moderate or interfere with the emergence of bullying situations. However, emotion is an input of feeling, and a relay station for thinking. When a positive interpretation is input, we will adopt actively positive actions to realize our goals. When a negative interpretation is input, we will not adopt actions or learn behaviors. Negative emotions are therefore particularly capable of producing learning difficulties [21]. From this literature, we can deduce that levels of emotional intelligence affect decisions with regard to negative behaviors related to being bullied, and thereby affect motivations for bullying. Petrides and Furnham (2001) point out that characteristics of emotional intelligence include the following: understanding of one's own emotions, properly managing one's emotions, self-motivation, recognizing others' emotions, and managing interpersonal relationships [22]. To sum up the above research findings, emotional intelligence not only positively affects peer relationships, but also negatively influences students' perceptions of being bullied, and thereby moderates and interferes with peer relationships and students' perceptions of being bullied. Thus, we proposed the fifth research hypothesis:

Hypothesis 5: Emotional intelligence exerts a moderating effect on peer relationships and perceptions of being bullied.

\section{RESEARCH METHODS}

\section{A. Research Framework}

The research framework for the present study (Fig. 1) was developed based on the review and analysis of relevant literature. This study used "Teacher Positive Discipline" as the independent variable, "Perception of Being Bullied" as the dependent variable, "Peer Relationships" as a mediator variable, and "Emotional Intelligence" as a moderator variable. These variables explore, respectively, the effect of positive discipline on peer relationships and perceptions of being bullied, the effect of peer relationships on the perception of being bullied, the mediating effect of peer relationships on positive discipline and perceptions of being bullied, and the moderating effect of emotional intelligence on peer relationships and perceptions of being bullied.

\section{B. Research Subjects and Analytical Methods}

The subjects of this study were senior primary school students in the Taiwan region; participants answer questionnaire base on their circumstances. This study used the cluster sampling method in which grades five and six in 
primary schools in the Taiwan region as two clusters. Subsequently, the simple random sampling method was used to select groups of students from classes, which was our final survey sample. After collecting questionnaires, this study screened, collated, recorded, and analyzed the data using regression analysis.

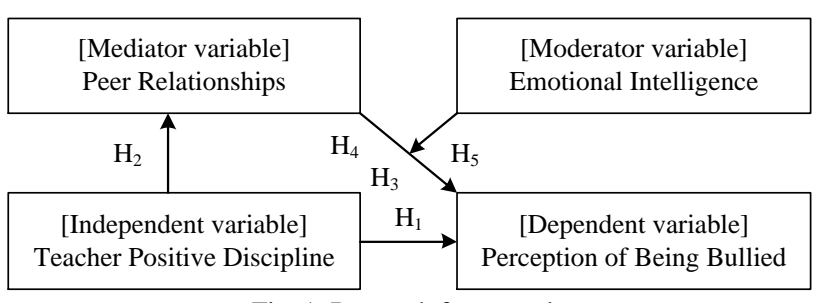

Fig. 1. Research framework.

\section{Research Tools, Reliability, and Validity}

The measurement tools used in this study included the following four scales, and basic data on subjects: "scale of emotional intelligence," "scale of perception of being bullied," "scale of peer relationships," and "scale of teachers' positive discipline." Herein, the content of the "scale of emotional intelligence" included the following five sub-scales: recognition of one's own emotions, proper emotion management, self-motivation, recognition of others' emotions, and management of interpersonal relationships [23]. The "scale of perception of being bullied" included the following three states of being bullied: "perception of verbal or relationship bullying," "perception of physical bullying behavior," and "perception of cyberbullying and sexual bullying" [24]. The "scale of peer relationships" uses positive peer relationships as its basis of measurement, and ties in with the effects of teachers' positive discipline [25]. The "scale of teacher positive discipline" distinguishes between the following three levels of positive discipline implementation: "atmosphere of positive support," "reasonable disciplinary practices," and "stable emotional management" [26], [27].

The Chronbach's $\alpha$ values for each of these dimensions were $0.90,0.92,0.80$, and 0.92 , respectively, showing adequate internal consistency. The results of the tests for validity and reliability in the present study were as follows. The reliability of each observed variable was greater than 0.30 . The construct reliability (CR) of each latent variable (teacher positive discipline, peer relationships, perception of being bullied, and emotional intelligence) was $0.73,0.70$, 0.81 , and 0.78 , respectively, while the overall model reliability was 0.75 (each of these values were higher than the standard value of 0.60). Furthermore, the average variance extracted (AVE) of latent variables was $0.48,0.51,0.56$, and 0.54 , respectively. The overall AVE was close to the standard value of 0.5 . Generally speaking, the CR and AVE of the main variables of this study exhibited good convergent validity and internal model quality.

\section{Mediator and Moderator Analyses}

Based on Baron and Kenny's (1986) analysis of mediator and moderator variables, this study utilized a complex regression model and path analysis to test the existence of mediator effects [28]. SPSS 18.0 was used to examine the descriptive statistics and related analyses of empirical data to support the research hypotheses. We use testing methods to understand the overall mediator and moderator effects of student peer relationships and emotional intelligence within the research framework. For this study's model, we use Amos 18.0 software to conduct a confirmatory factor analysis on the structural equation models, after which a complex regression analysis was used to test for effects between variables as a means of conducting hypothesis testing. Because this study only used a self-report questionnaire, at one time-point, to collect data on the research variables, the results of this study may exhibit the risk of common method variance [29]. However, previous studies have noted that the significance of moderator effects are generally not affected by common method variance [30], [31]. This study used a self-report scale to collect data on perceptions from individual participants, and therefore, it was affected by the limitations related to the common method variance.

\section{RESEARCH RESULTS}

\section{A. Analysis of Basic Data and Descriptive Statistics}

Public primary schools in the Taiwan region fell under the present study's research scope, and formally enrolled senior primary school students in the northern, central, southern, and eastern regions of Taiwan comprised its sample. According to the regional proportions of schools, we conducted a stratified random sampling survey. This study distributed 1,600 questionnaires, and with the help of the academic affairs units of each school. After eliminating invalid questionnaires, 1,100 valid questionnaires were collected, with a collection rate of about $69.38 \%$. Majority of the sample comprised girls (558 girls [50.3\%] and 552 boys [49.7\%]). With regard to grade level, 572 students were in grade five $(51.5 \%)$, while 536 were in grade six $(48.5 \%)$. The mean, standard deviation (SD), and correlation coefficient for each research variable have been presented in Table I. The Person's correlations for each variable reached the level of statistical significance.

TABLE I: MEANS, STANDARD DEVIATIONS, AND CORRELATION COEFFICIENTS OF THE STUDY VARIABLES

\begin{tabular}{lcccccc}
\hline \hline Variable & Mean & $\begin{array}{c}\text { Standard } \\
\text { Deviation }\end{array}$ & 1 & 2 & 3 & 4 \\
\hline $\begin{array}{l}1 \text { Teacher } \\
\text { Positive } \\
\text { Discipline }\end{array}$ & 4.036 & .835 & 1 & & & \\
$\begin{array}{l}2 \text { Perception } \\
\text { of Being } \\
\text { Bullied }\end{array}$ & 1.429 & .585 & $-.098^{* *}$ & 1 & & \\
$\begin{array}{l}3 \text { Peer } \\
\text { Relationships }\end{array}$ & 1.421 & .741 & $-.393 * *$ & $-.295^{* *}$ & 1 & \\
$\begin{array}{l}\text { 4 Emotional } \\
\text { Intelligence }\end{array}$ & 2.792 & .638 & $.117 * *$ & $-.326 * *$ & $-.275^{* *}$ & 1 \\
\hline
\end{tabular}

\section{B. Regression Analysis}

First, this study used regression analysis to analyze the effect of teachers' positive discipline on peer relationships, and perceptions of being bullied. Next, we analyzed the effect of peer relationships on perceptions of being bullied (Table II). 1) The $\beta$ value of the effect of teachers' positive 
discipline on peer relationships was 0.938 ( $p$-value $<0.001$, $R^{2}=0.156, F=202.640$ ), indicating a significant effect. 2 ) The $\beta$ value of teacher positive discipline on perceptions of being bullied was $-0.086\left(p<0.05, R^{2}=0.043, F=8.535\right)$, indicating a significant effect. The $\beta$ value for the effect of peer relationships on perceptions of being bullied was -0.276 ( $\left.p<0.001, R^{2}=0.110, F=92.367\right)$, indicating a significant effect. These results reveal that a teacher's positive discipline has a significant and positive effect on peer relationships, and a significant and negative effect on perceptions of being bullied. Thus, Hypothesis 1 and Hypothesis 2 were supported Furthermore, peer relationships have a significant and negative effect on perceptions of being bullied; thus, Hypothesis 3 was also supported.

TABLE II: RESULTS OF THE HIERARCHICAL REGRESSION ANALYSIS ON THE EFFECT OF TEACHER POSITIVE DISCIPLINE ON PEER RELATIONSHIPS AND PERCEPTIONS OF BEING BULLIED

\begin{tabular}{|c|c|c|c|c|}
\hline \multirow{2}{*}{$\begin{array}{l}\text { Dependent } \\
\text { Variable } \\
\text { Independent } \\
\text { Variable }\end{array}$} & \multicolumn{4}{|c|}{ Peer Relationships Perception of Being Bullied } \\
\hline & $\begin{array}{c}\text { Model } \\
1 \\
\end{array}$ & Model 2 & Model 1 & Model 2 \\
\hline Gender & ב.023 & -.031 & $-.060 *$ & $-.058^{*}$ \\
\hline $\begin{array}{l}\text { Grade } \\
\text { Teacher }\end{array}$ & .017 & -.015 & $-.180 * *$ & $-.179 * *$ \\
\hline $\begin{array}{l}\text { Positive } \\
\text { Discipline }\end{array}$ & & $.398 * * *$ & & $-.086^{*}$ \\
\hline $\mathrm{R}^{2}$ & .001 & .156 & .036 & .043 \\
\hline$\Delta \mathrm{R}^{2}$ & .001 & .155 & .036 & .007 \\
\hline $\mathrm{F}$ & .467 & $202.640 * * *$ & $20.535 * * *$ & $8.535 * *$ \\
\hline Gender & & & $-.060^{*}$ & -.022 \\
\hline Grade & & & $-.180 * * *$ & $-.158 * * *$ \\
\hline $\begin{array}{l}\text { Peer } \\
\text { Relationships }\end{array}$ & & & & $-.276^{* * *}$ \\
\hline $\mathrm{R}^{2}$ & & & .036 & .110 \\
\hline$\Delta \mathrm{R}^{2}$ & & & .036 & .074 \\
\hline $\mathrm{F}$ & & & $20.535 * * *$ & $92.367 * * *$ \\
\hline
\end{tabular}

Note: $* p<0.05 ; * * p<0.01 ; * * * p<0.001$

Next, we tested the mediating effect of peer relationships with regard to teacher positive discipline and perceptions of being bullied (Table III). In Model 2, the effect of teacher positive discipline on perceptions of being bullied had a $\beta$ value of $-0.086\left(p<0.01, R^{2}=0.043, F=8.535\right)$, indicating a significant effect. In the regression model for Model 3, when we included the variable for peer relationships, the effect of teacher positive discipline on perceptions of being bullied had a $\beta$ value of 0.025 , and the mediating effect was not significant. When the mediator variable (peer relationships) was included in the model, the predictive power of teacher positive discipline declined from the original value of 0.086 (significant) to 0.025 (nonsignificant); however, the explanatory power, $\mathrm{R}^{2}$, increased from 0.043 (significant, $F=8.535$ ) to 0.107 (significant, $F=83.835$ ). The effect of peer relationships on perceptions of being bullied had a $\beta$ value of $-0.286\left(p<0.001, R^{2}=0.107, F=83.835\right)$. These results show that peer relationships had a partial mediating effect on teacher positive discipline and perceptions of being bullied. Thus, Hypothesis 4 was supported.

Finally, we tested the moderator effect of emotional intelligence on peer relationships and perceptions of being bullied (Table IV). 1) In Model 2, peer relationships and perceptions of being bullied had a $\beta$ value of $-0.276(p<0.01$, $R^{2}=0.110, F=92.367$ ). 2) In Model 3, emotional intelligence and perceptions of being bullied had a $\beta$ value of 0.026 . 3) In Model 4 , the interaction effect of peer relationships and emotional intelligence had a $\beta$ value of $0.70(p<0.05)$. These results show that emotional intelligence had a moderating effect on peer relationships and perceptions of being bullied. It is more noteworthy that the interaction effect of "peer relationships" and "emotional intelligence" on "perceptions of being bullied" was significant and positive. According to the Table IV shows data we know that "high emotional intelligence participants" had a more positive influence on peer relationships to "perceptions of being bullied" as compared to "low emotional intelligence participants" In other words, when students have high emotional intelligence, one should concentrate more on their establishment of peer relationships to effectively reduce instances of bullying. Thus, Hypothesis 5 was supported.

TABLE III: RESULTS OF THE MODERATOR HIERARCHICAL REGRESSION ANALYSIS OF EFFECTS OF TEACHER POSITIVE DISCIPLINE ON PEER RELATIONSHIPS AND PERCEPTIONS OF BEING BULLIED

\begin{tabular}{|c|c|c|c|}
\hline \multirow{2}{*}{$\begin{array}{l}\text { Dependent } \\
\text { Variable } \\
\text { Independent } \\
\text { Variable }\end{array}$} & \multicolumn{3}{|c|}{ Perception of Being Bullied } \\
\hline & Model 1 & Model 2 & Model 3 \\
\hline Gender & $-.060 *$ & $-.058 *$ & -.021 \\
\hline Grade & $-.180 * * *$ & $-.179 * * *$ & $-.157 * * *$ \\
\hline Teacher & & & \\
\hline Positive & & $-.086^{* *}$ & .025 \\
\hline Discipline & & & \\
\hline Peer & & & $-286 * * *$ \\
\hline Relationships & & & -.280 \\
\hline $\mathrm{R}^{2}$ & .036 & .043 & .107 \\
\hline$\Delta \mathrm{R}^{2}$ & .036 & .007 & .067 \\
\hline $\mathrm{F}$ & $20.535 * * *$ & $8.535 * *$ & $83.835 * * *$ \\
\hline
\end{tabular}

TABLE IV: RESULTS OF THE MODERATOR VARIABLE HIERARCHICAL REGRESSION ANALYSIS

\begin{tabular}{lcccc}
\hline \hline $\begin{array}{l}\text { Dependent } \\
\text { Variable } \\
\text { Independent }\end{array}$ & \multicolumn{3}{c}{ Perception of Being Bullied } \\
\cline { 2 - 5 } Variable & Model 1 & Model 2 & Model 3 & Model 4 \\
\cline { 2 - 5 } Gender & -.060 & -.022 & -.023 & -.027 \\
Grade & -.180 & -.158 & -.023 & -.157 \\
Peer Relationships & & $-.276^{*} *$ & $-.289 * *$ & $-.285^{*} *$ \\
Emotional & & & .026 & .046 \\
Intelligence & & & & \\
Peer & & & $.070 *$ \\
Relationships*Em & & & .110 & .115 \\
otional Intelligence & .036 & .074 & .001 & .004 \\
$\mathrm{R}^{2}$ & .036 & $92.367 *$ & .636 & $5.577 *$ \\
$\Delta$ R & $20.535^{2}$ & $*$ & & \\
$\mathrm{~F}$ & $*$ & & & \\
\hline \hline
\end{tabular}

Note: $* p<0.05 ; * * p<0.01$

As evident from the complex regression diagram presented in Fig. 2, for students with high emotional intelligence, those with better peer relationships had lower perceptions of being bullied. However, the same was true for those students with low emotional intelligence; when they had better peer relationships, they had lower perceptions of being bullied. However, for students with high emotional intelligence and low emotional intelligence, the effect of peer relationships on perceptions of being bullied was negative, and the two groups did not vary greatly. The quality of peer relationships has a larger effect on perceptions of being bullied for students of high emotional intelligence when compared with that for 
students of low emotional intelligence. Thus, students with high emotional intelligence and good peer relationships can experience a relatively low incidence of being bullied.

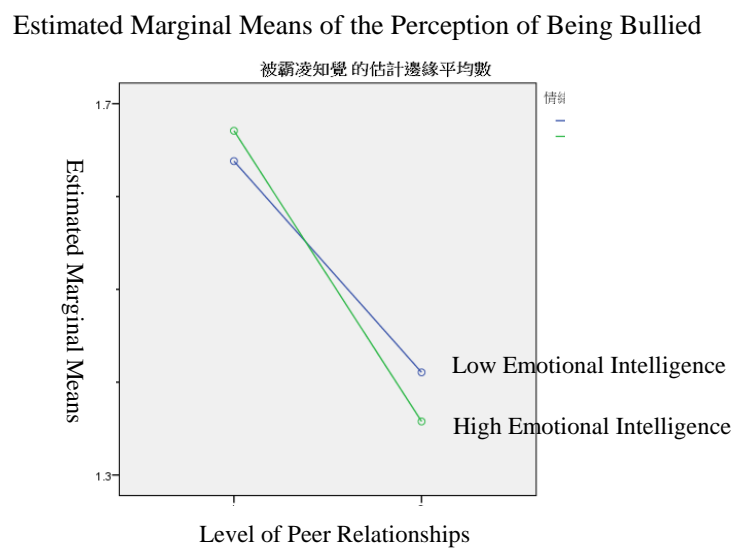

Fig. 2. Moderator effect of emotional intelligence on peer relationships and perception of being bullied.

In summary of the above analysis, the results of this study's hypothesis testing are as follows:

H1: Positive discipline by teachers has a significant and positive effect on peer relationships; verification results supported this hypothesis.

H2: Positive discipline by teachers has a significant and negative effect on perceptions of being bullied; verification results supported this hypothesis.

H3: Peer relationships have a significant and negative effect on perceptions of being bullied; verification results supported this hypothesis.

H4: Positive discipline by teachers affects perceptions of being bullied through the partial mediator effect of peer relationships; verification results supported this hypothesis.

H5: Emotional intelligence exerts a partial moderator effect on peer relationships and perceptions of being bullied; verification results supported this hypothesis.

\section{Discussion AND CONCLUSIONS}

\section{A. Conclusions}

This study explored the relationships between and effects of the following four variables: positive discipline by teachers, peer relationships, perceptions of being bullied, and emotional intelligence. Regardless of whether we consider academic research or empirical teaching, by discussing these four elements together, we can explain their effects more succinctly. The results of this study verified all of our research hypotheses. Herein, we discovered that peer relationships have a partial mediating effect on positive discipline by teachers and perceptions of being bullied. Emotional intelligence has a moderating effect on peer relationships and perceptions of being bullied, and this moderating effect passes through the mediating influence of peer relationships to indirectly affect students' perceptions of being bullied; this was also supported by our empirical results. This result has substantial significance for education. Additionally, with regard to the influence of positive discipline by teachers in schools on perceptions of being bullied, although relevant research by other academics has already proven this effect, an important discovery of this study is that, through the mediating effect of peer relationships, the efficacy of perceptions of being bullied is affected.

Facing the complicated and changing teaching requirements in educational environments, and given the background of undeveloped student moral values and strong senses of parental autonomy, it is increasingly difficult to harness the influence of school education, and class management is becoming increasingly difficult for teachers. Future teachers will face even greater challenges and more significant stress. Therefore, the question of how to use the educational concept of positive discipline to effectively manage the changing and complex students and their personal problems in future is a challenging one. The key to "protecting students from the troubles of bullying" is to "keep up with the times through innovating and demanding change," by using the first line of education, teachers, to guide students in establishing good "peer relationships" and by improving students' "emotional intelligence."

\section{B. Recommendations}

\section{1) Positive discipline by teachers}

Research shows that positive discipline by teachers has a significant effect on peer relationships and perceptions of being bullied. Looking at the current disciplining methods of teachers in Taiwan's primary schools, most use patriarchal or authoritative methods. If teachers were to adopt the positive discipline method, they could not only show professional accomplishment but could also teach students to use positive attitudes and positive thinking when interacting with peers. Students who have bullying tendencies may also be encouraged to learn empathy and to interact peacefully with other students through the words and actions of their teachers. Thus, we suggest that teacher training is used to strengthen teachers' knowledge and practice of positive discipline. Teachers who are already working may use a variety of training channels to enrich their knowledge of positive discipline, and in this way, in addition to benefitting the professional skills of teachers, students of such teachers are even more likely to benefit from improved peer relationships and reduced bullying.

\section{2) Perception of being bullied}

The results of this study show that positive discipline by teachers reduces opportunities for bullying. Therefore, we suggest that when teachers implement positive discipline, they first implement all steps and practices of the "Campus Bullying Prevention Guidelines" in a timely manner, and establish anti-bullying concepts and bullying-prevention concepts in students as a means of effectively raising schools' and individuals' sensitivity to bullying and bullying response mechanisms. Next, schools should carefully plan appropriate professional courses for bullying prevention in order to provide teachers with quality opportunities to learn positive discipline. At the same time, it is necessary to integrate relevant teaching resources, properly distribute and apply these resources, and incorporate educational training into performance assessments in order to strengthen the learning outcomes of schools' teaching staff. Finally, schools 
should use knowledge management technology to organize bullying prevention communities, establish bullying prevention knowledge exchange platforms, and supplement these efforts with competition and incentive measures to effectively establish, utilize, and share knowledge on the management and prevention of bullying.

\section{3) Peer relationships}

The results of this study show that when peer relationships are considered, the individual effect of positive discipline by teachers on perceptions of being bullied will decline. This result explains that peer relationships play a mediator role with teachers' positive discipline and perceptions of being bullied. This phenomenon also tells us that, with regard to students in the senior stage of primary school, good peer relationships play a relatively important role. Thus, this study recommends that, in addition to teaching students class-related knowledge, teachers should generally pay greater attention to and observe the state of students' peer interactions, and give timely guidance and help students to correct improper views. In this process of guidance, teachers can use role playing techniques of situational teaching to allow students to experience the role of bullying victims, and thereby they can clarify values more effectively.

\section{4) Emotional intelligence}

According to the results of this study, emotional intelligence plays a moderating role in peer relationships and perceptions of being bullied. Furthermore, this moderating role can indirectly affect students' perceptions of being bullied through the mediating role of peer relationships. This shows that students with high levels of emotional intelligence experience higher levels of negative effects with regard to peer relationships and perceptions of being bullied when compared with students of low emotional intelligence. Therefore, we recommend that, first, coursework related to emotional intelligence studies are increased, and that class performance systems are actively promoted in order to encourage teachers to emphasize on emotional intelligence education and course quality. Secondly, we recommend that emotional intelligence testing systems are established, test results are used to identify students who may require emotional counseling, and that assistance and guidance is provided to address different emotional disorders. Thirdly, we recommend that channels for emotional expression and venting are provided; according to different emotional characteristics, careful assessment should be made and expert guidance should be provided. By providing multiple appropriate methods for emotional expression, students can be helped to improve their peer relationships by improving their emotional intelligence, which in turn will reduce the risk of bullying.

\section{REFERENCES}

[1] J. Nelsen, Positive Discipline, Ballantine Books, 2011.

[2] K. Rigby, P. T. Slee, and G. Martin, "Implications of inadequate parental bonding and peer victimization for adolescent mental health," J. Adolesc., vol. 30, no. 5, pp. 801-812, 2007.

[3] C. Lopez and D. L. DuBois, "Peer victimization and rejection: Investigation of an integrative model of effects on emotional, behavioral, and academic adjustment in early adolescence," J. Clin. Child Adolesc. Psychol., vol. 34, no. 1, pp. 25-36, 2005.
[4] E. Beauport and A. S. Diaz, The Three Faces of Mind: Developing Your Mental, Emotional, and Behavioral Intelligences, Wheaton, Illinois: Quest Books, 1996.

[5] T. Good and J. Brophy, Contemporary Educational Psychology, White Plains, N.Y: Longman, 1995.

[6] W. L. Payne, "A study of emotion: Developing emotional intelligence; Self-integration; relating to fear, pain and desire," Ph.D. dissertation, Department, The Union for Experimenting Colleges and University, Ohio, 1985 .

[7] P. Salovey and J. D. Mayer, "Emotional intelligence," Imagin. Cogn. Pers., vol. 9, pp. 185-211, 1990.

[8] K. P. Allen, "Classroom management, bullying, and teacher practices," Prof. Educator, vol. 34, no. 1, pp. 1-15.

[9] Y.-S. Lin et al., A One Inch Olive Branch: Campus Bullying and Prevention Strategies, Taipei: Shinning Culture Publishing Co., 2014.

[10] M. Seligman, Learned Optimism, New York: Pocket Books, 1998.

[11] W. Carlson and A. J. Rose, "The role of reciprocity in romantic relationship in middle childhood and early adolescence," Merrill Palmer Q., vol. 53, no. 2, pp. 262-290, 2007.

[12] G. Colvin, E. J. Kameenui, and G. Sugai, "Reconceptualizing behavior management and school-wide discipline in general education," Education Treatment of Children, vol. 16, no. 4, pp. 361-381, 1993.

[13] G. Sugai, R. H. Horner, R. Algozzine, S. Barrett, T. Lewis, C. Anderson, and B. Simonsen, School-Wide Positive Behavior Support: Implementers' Blueprint and Self-assessment, Eugene, OR: University of Oregon, 2010.

[14] S. Perren and F. D. Alsaker, "Social behavior and peer relationships of victims, bully-victims, and bullies in kindergarten," J. Child Psychol. Psychiatr., vol. 47, no. 1, pp. 45-57, 2006.

[15] E. Murgui and Mustiu, "Listening to students: Mentorship in graduate education," Change, vol. 41, no. 1, pp. 55-56, 2009.

[16] R. J. Hazler and S. A. Denham, "Social isolation of youth at risk: Conceptualizations and practical implications," J. Couns. Dev., vol. 80, pp. 403-409, 2002

[17] J. G. Parker and S. R. Asher, "Peer relations and later personal adjustment: Are low-accepted children at risk," Psychol. Bull., vol. 102, pp. 357-389, 1987.

[18] K. H. Rubin and S. L. Stewart, "Social withdrawal," in Child Psychopathology, E. J. Mash and R. A. Barkley, Eds. New York: The Guilford Press, 1996.

[19] J. B. Kupersmidt, J. D. Coie, and K. A. Dodge, "The role of poor peer relationships in the development of disorder," in Peer Rejection in Childhood, S. R. Asher and J. D. Coie, Eds., New York: Cambridge University Press, 1990.

[20] M. A. Brackett, P. N. Lopes, Z. Ivcevic, J. D. Mayer, and P. Salovey, "Integrating emotion and cognition: The role of emotional intelligence," Motivation, Emotion, and Cognition: Integrating Perspectives on Intellectual Functioning, 2004, pp. 175-194.

[21] D. Goleman, Working with Emotional Intelligence, New York: Bantam Books, 1998.

[22] K. V. Petrides and A. Furnham, "Trait emotional intelligence: Psychometric investigation with reference to established trait taxonomies," Eur. J. Pers., vol. 15, pp. 425-448, 2001.

[23] Q.-L. Chen et al., "Emotional intelligence and happiness: A study of interpersonal relationships and personality," Master's thesis, Dept. of XX, National Pingtung University of Education, Pingtung County, Country, 2001

[24] J.-C. Lin et al., The Complete Anti-Bullying Handbook: Cases and Strategies.

[25] Z.-X. Wu et al., "Taiwan children and youth relationship scale" A Study on the Establishment of a Psychological Measurement Scale," Psychol. Test, vol. 55, no. 3, pp. 535-557, 2008.

[26] Y.-H. Ou et al., "Implementation of positve discipline in Taoyuan county primary schools," Master's thesis, National Hsinchu University of Education College of Education, Hsinchu City, Country, 2012.

[27] Z.-Y. Li et al., "Relationship between positive discipline and class management efficacy in Taichung primary schools," Feng Chia University Graduate Institute of Public Affairs, Taichung City, Country, 2013

[28] B. M. Baron and D. A. Kenny, "The moderator-mediator variable distinction in social psychological research: Conceptual, strategic, and statistical considerations," J. Pers. Soc. Psychol., vol. 51, no. 6, pp. 1173-1182, 1986.

[29] P. M. Podsakoff et al., "Common method biases in behavioral research: A critical review of the literature and recommended remedies," Journal of Applied Psychology, vol. 88, no. 5, pp. 879-903, 2003.

[30] C.-Y. Wu et al., "Competent authority, subordinate job satisfaction, and organizational commitment: The mediating effect of trust and 
moderating effect of emotional intelligence," Indigenous Psychological Research in Chinese Studies, vol. 30, pp. 3-63, 2008.

[31] L. S. Aiken and S. G. West, Multiple Regression: Testing and Interpreting Interactions, Newbury Park, CA: Sage, 1991.

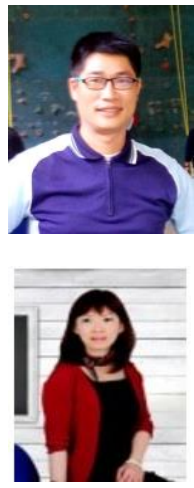

Lung-Fan Wei is doctoral student at the Department of Industrial Education and Technology, National Changhua University of Education. His academic interests include e-learning, emotional intelligence, education administration, and classroom management.

Shu-Hsuan Chang is a professor of the Department of Industrial Education and Technology, National Changhua University of Education. Her academic interests include e-learning, engineering education, and technological and vocational education.
Chung-Yu Lin is a master graduate student at the Department of Industrial Education and Technology, National Changhua University of Education. His academic interests include education administration, educational psychology, and teaching design. 